\title{
Recovery of Nickel from Reformer Catalysts of Direct Reduction, Using the Pressurized Dissolving Method in Nitric Acid
}

\author{
Behdad Abrar \\ Department of Materials Science and \\ Technology \\ Sharif University of Technology \\ Tehran, Iran
}

\author{
Mohammad Halali \\ Department of Materials Science and \\ Technology \\ Sharif University of Technology \\ Tehran, Iran
}

\author{
Ali Pourfathi \\ Department of Materials Science and \\ Technology \\ Sharif University of Technology \\ Tehran, Iran
}

\begin{abstract}
In the process of direct reduction of iron pellet and production of sponge iron, $\mathrm{NiO} / \mathrm{Al}_{2} \mathrm{O}_{3}$ act as a catalyst for the generation of carbon monoxide and hydrogen by vapor and natural gas. As an expensive material used in MIDREX method for steel units, this type of catalyst has major environmental problems after accumulation. The steel industry in Iran hopes to employ the MIDREX technique for the 80 percent of the 50 million tons of steel. Thus, the problem of spent catalysts will become a serious environmental challenge. Through the hydrometallurgy method, the present study investigates a possible solution to the problem of catalyst depot (due to heavy metals such as nickel) via nickel recovery, which may increase the possibility of selling or re-using the precious and expensive metal. The present research studied the Nickel recovery from spent catalysts of $\mathrm{NiO} / \mathrm{Al}_{2} \mathrm{O}_{3}$ used in reduction gas reliefs of the production of sponge iron unit. In this study, the parameters of temperature, concentration, time and Rpm were studied using pressurized dissolving method. $100 \%$ efficiency was achieved at $140{ }^{\circ} \mathrm{C}$ for 120 minutes, nitric acid concentration of $1.5 \mathrm{~mm}, \mathrm{Rpm}$ of 600 and $40 \mathrm{~s} / \mathbf{1} 40$ grams per liter.
\end{abstract} nickel

Keywords-catalyst; high-pressure hydrogenation; nitric acid;

\section{INTRODUCTION}

Hydrometallurgical methods and processes are considered as environmental-friendly by the metal recycling industry of various sources. The benefits of such techniques includes low energy consumption, production of less gas pollutants and products, production of less waste and maximum recovery compared to other methods [1]. Catalyst consumption and thus production of spent catalysts is increasing with a tremendous rate, and the global growth is estimated to be about $4.4 \%$. [2]. It is estimated that the current worldwide value of these wastes is between 150,000 to 170,000 tons per year [3]. Spent catalysts are considered as secondary sources of some valuable elements. In recent years, many studies have been conducted to recover various metals from the waste. Catalysts discussed here were mainly used in the steel industry and oil and petrochemical processes such as desulphurization hydrocracking, synthesis of methane and ammonia, hydrogenation etc. The catalyst are usually alumina or silicabased with some elements added to them which includes: molybdenum, nickel, tungsten, platinum, rhenium, vanadium, zinc, copper, cobalt and chromium or their oxides. The catalyst examined in this study is $\mathrm{Al}_{2} \mathrm{O}_{3} / \mathrm{NiO}$ and the focus of interest is the recovery of nickel from the waste. Nickel oxide containing catalysts are often used as a catalyst in the process of reforming and hydrocracking [4].

\section{MIDREX PROCESS}

The process of reforming is defined as the hydrocarbons reaction with oxidants such as water vapor and carbon dioxide to produce a mixture of hydrogen and carbon monoxide. Usually, nickel is taken as catalyst in such process. The number of reactions that occur in the methane reforming condition is high and the most important types are as the following:

$$
\begin{aligned}
& \mathrm{CH}_{4}+\mathrm{H}_{2} \mathrm{O} \leftrightarrow \mathrm{CO}+3 \mathrm{H}_{2} \\
& \mathrm{CO}+\mathrm{H}_{2} \mathrm{O} \leftrightarrow \mathrm{CO}_{2}+\mathrm{H}_{2} \\
& \mathrm{CH}_{4}+2 \mathrm{H}_{2} \mathrm{O} \leftrightarrow \mathrm{CO}_{2} 4 \mathrm{H}_{2} \\
& \mathrm{CH}_{4}+\mathrm{CO}_{2} \leftrightarrow 2 \mathrm{CO}+2 \mathrm{H}_{2}
\end{aligned}
$$

Steam reforming of natural gas is the most important and most economical process for production of synthesis gas in petrochemical and steel plants. The synthesis gas is consumed in production units of methanol, ammonia, and in refining and production of sponge iron. In the production units of sponge iron, iron ore is reduced under atmospheric pressure by synthesis gas. The processes for producing synthesis gas used in these units are used in or near atmospheric pressure. In the MIDREX process, natural gas at a temperature of about $1200 \mathrm{~K}$ in plug tube fixed bed reformers reacts with steam and as a result the synthesis gas is produced. 


\section{METHODOLOGY}

In order to achieve the research objectives, first in the study investigation and study of the domestic and foreign research activities conducted on spent catalysts used in MIDREX process were considered. But since MIDREX method and in general a method for production of sponge iron (DRI) by using natural gas is specialized to the countries with huge gas reserves (first of all Iran), considerable researches have not been conducted on this matter and recovery of the precious metals contained in it (including nickel). As a result, in the study phase, we focused on the similar catalysts of this method $\left(\mathrm{Al}_{2} \mathrm{O}_{3} / \mathrm{NiO}\right)$ in other industries such as petrochemical, oil and gas, and production of chemical fertilizer and vegetable oil.

Similar studies have been conducted by various researchers. In [5], the acidic recovery of Nickel from spent catalysts used in the industry of production of palm oil in Malaysia was studied. In [6], optimizing the parameters for extraction of nickel, molybdenum, vanadium and aluminum from spent catalyst using oxalic acid catalyst in the presence of hydrogen peroxide was investigated. In [7], the two-step dissolving first by ammonia and then by $10 \%$ sulfuric acid was investigated. In [8], the authors used two-step dissolving to recover metals present in the catalyst. In [9], the recovery of molybdenum, nickel, cobalt and aluminum from spent catalysts using the alkaline and acidic two-stage dissolving approach was studied. In [10], the authors investigated the catalyst dissolving using acidized bacteria. In [11], the recovery of nickel from hydrogenation catalyst using Thiobacillus Thiuoxidane as a solver agent and the DesulfosuccinatesVibrio5 bacteria as dissolving agent was investigated [11]

\section{EXPERIMENTAL METHODS}

\section{A. Materials}

Precursor materials used in the study consisted of catalyst $\left(\mathrm{NiO} / \mathrm{Al}_{2} \mathrm{O}_{3}\right)$ spent in the direct reduction gas reliefs (MIDREX method) of Khuzestan Steel Company, nitric acid $65 \%$ Merck, distilled water processed in the extraction of metals laboratory of Sharif University of Technology, Iran. The catalyst used in this study approximately consisted of $12.5 \%$ nickel in the form of nickel oxide based on alpha alumina phase (insoluble in nitric acid), form the major part of the catalyst (approximately $85 \%)$.

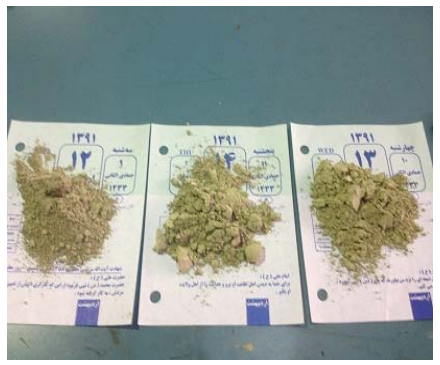

Fig. 1. The powder used

\section{B. Catalyst preparation}

The catalysts used in this study require preparation before dissolving, because of the special working conditions under which they have been spent. Normally gas relief catalysts act as the reaction catalyst at a temperature of about $1000{ }^{\circ} \mathrm{C}$ and produce the hydrogen and carbon monoxide gases in order to reduce the iron pellets. But part of the sulfur in the natural gas together with sulfur and carbon in the gas recycled from the MIDREX furnace that again put under the reaction, have deposited on the surface of the catalyst and after an hour lead to poisoning of the catalyst which is then dumped into the drain. This is done in order to remove carbon and specially sulfur from the surface of catalyst, which disrupt the nickel dissolving process. In this study, before the crushing operations, roasting operation was performed to remove sulfur and carbon, so that the catalysts were put in the furnace at $700{ }^{\circ} \mathrm{C}$ and under laminar flow of air, they were heat treated for 4 hours. The results of XRF analysis of catalysts showed that the most important elements in the catalyst was aluminum (43\%) in the form of aluminum oxide and nickel $(12.15 \%)$ in the form of nickel oxide.

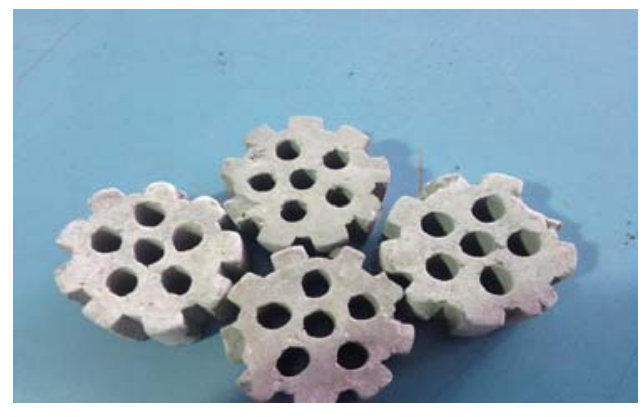

Fig. 2. Spent catalysts

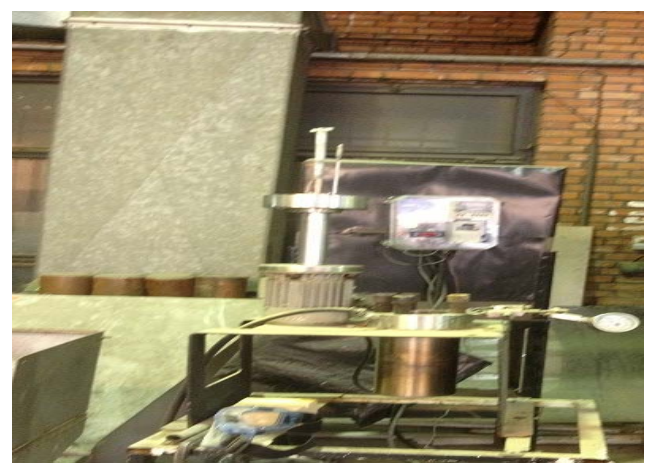

Fig. 3. The reactor used

\section{Experimental method}

Since pressurized dissolving method was less used, we decided to use this method for tests, considering its advantages (according to the Clausius-Clapeyron relationship, increase of pressure also increases the evaporation temperature). As a result tests can be carried out at higher temperatures. By increasing the temperature, dissolving time can be reduced and also lower concentrations of acid may be used. 
Also, argon gas was used for the implementation of pressurized environment, which was less risky than hydrogen, despite oxygen does not react with solution. In addition, an argon gas capsule was available in the laboratory. Besides the nitric acid was used which was stronger compared to sulfuric acid. Variables of temperature, time, concentration and effectiveness of the rpm on dissolution efficiency were studied. However, although at first seeds of different sizes were available in the laboratory, the aim of the study was not to study the effect of particle size, so the grain size was selected to be +1 . In addition, pressure was constant at 10 bar and solid to liquid ratio was 40 grams per liter. In order to study the effect of Temperature, 4 tests were conducted where temperature varies whereas other factors are kept constant (Table I). A similar approach was followed to investigate the effects of concentration (Table II) and time (Table III). Five runs were conducted in the latter case to increase the accuracy. To investigate the effect of Rpm, a comparison mode was taken between 300 and 600 while other parameters were fixed as just the effectiveness of efficiency on it was examined (Table IV).

\section{RESULTS AND DISCUSSION}

A comparison of dissolving results vs temperature is shown in Table V. As shown, an increase of temperature led to an increase of the dissolution efficiency. The results of Table $\mathrm{V}$ show that the increase of temperature has an optimization effect. The reason may be because of the increase of acid evaporation rate. After raising the temperature, two factors compete each other. One of them is the increase of temperature which enhances the efficiency and another is the excess reduction of acid concentration after the optimum temperature. Of course the optimum temperature can be improved by raising the system pressure. Also we should point out that after a while increase of temperature is not effective, which is probably because of dissolution of whole nickel in the solution and so increase of time would not affect the efficiency. Results of tests conducted to check the effects of acid concentration are given in Table VI. As shown, by doubling the concentration, the dissolving efficiency was also approximately doubled. This can due to an increase to the molarity of acid solution which may help more nickel to move to the solution from the dust. The results from the investigation of the effect or Rpm changes are shown in Table VII.

TABLE I. TEMPERATURE EFFECT

\begin{tabular}{|c|c|c|c|c|c|c|c|}
\hline 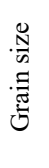 & $\underbrace{\overparen{E}}_{\text {Ẽ }}$ & 苂 & 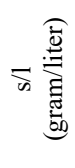 & 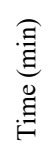 & 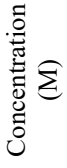 & 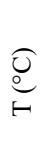 & 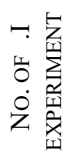 \\
\hline+1 & 10 & 600 & 40 & 120 & 1.5 & 110 & 1 \\
\hline+1 & 10 & 600 & 40 & 120 & 1.5 & 120 & 2 \\
\hline+1 & 10 & 600 & 40 & 120 & 1.5 & 130 & 3 \\
\hline+1 & 10 & 600 & 40 & 120 & 1.5 & 140 & 4 \\
\hline
\end{tabular}

TABLE II. CONCENTRATION EFFECT

\begin{tabular}{|c|c|c|c|c|c|c|c|}
\hline 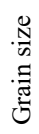 & $\begin{array}{l}\overparen{\bar{E}} \\
\underbrace{0}_{0}\end{array}$ & 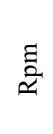 & 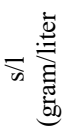 & 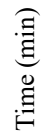 & 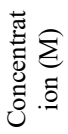 & $\underbrace{0}_{f}$ & 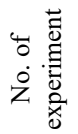 \\
\hline+1 & 10 & 600 & 40 & 120 & 0.25 & 120 & 1 \\
\hline+1 & 10 & 600 & 40 & 120 & 0.50 & 120 & 2 \\
\hline+1 & 10 & 600 & 40 & 120 & 1 & 120 & 3 \\
\hline+1 & 10 & 600 & 40 & 120 & 1.5 & 120 & 4 \\
\hline
\end{tabular}

TABLE III. TIME EFFECT

\begin{tabular}{|c|c|c|c|c|c|c|c|}
\hline 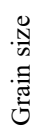 & $\begin{array}{l}\widehat{\bar{E}} \\
\text { Ẽ } \\
\text { a }\end{array}$ & 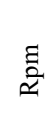 & क & 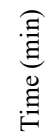 & 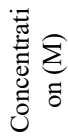 & $\underbrace{0}_{f}$ & 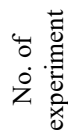 \\
\hline+1 & 10 & 600 & 40 & 15 & 1.5 & 120 & 1 \\
\hline+1 & 10 & 600 & 40 & 30 & 1.5 & 120 & 2 \\
\hline+1 & 10 & 600 & 40 & 60 & 1.5 & 120 & 3 \\
\hline+1 & 10 & 600 & 40 & 90 & 1.5 & 120 & 4 \\
\hline+1 & 10 & 600 & 40 & 120 & 1.5 & 120 & 5 \\
\hline
\end{tabular}

TABLE IV. RPM EFFECT

\begin{tabular}{|c|c|c|c|c|c|c|c|}
\hline 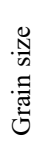 & 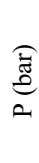 & ڤ్ & 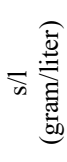 & 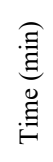 & 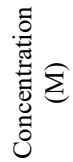 & $\underbrace{0}_{\models}$ & 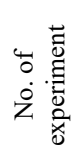 \\
\hline+1 & 10 & 600 & 40 & 120 & 1.5 & 120 & 1 \\
\hline+1 & 10 & 300 & 40 & 120 & 1.5 & 120 & 2 \\
\hline
\end{tabular}

TABLE V. COMPARISON OF DISSOLVING RESULTS AT DIFFERENT TEMPERATURES

\begin{tabular}{|c|c|c|c|c|c|c|c|}
\hline 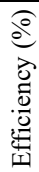 & 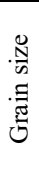 & $\overbrace{\text { Ẽ }}^{\stackrel{E}{E}}$ & ڤ્a & 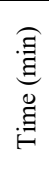 & 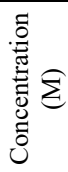 & $\underbrace{0}_{\in}$ & 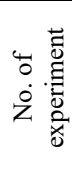 \\
\hline 34 & +1 & 10 & 600 & 120 & 1.5 & 110 & 1 \\
\hline 66 & +1 & 10 & 600 & 120 & 1.5 & 120 & 2 \\
\hline 85 & +1 & 10 & 600 & 120 & 1.5 & 130 & 3 \\
\hline 98 & +1 & 10 & 600 & 120 & 1.5 & 140 & 4 \\
\hline
\end{tabular}

TABLE VI. COMPARISON OF DISSOLVING RESULTS AT DIFFERENT ACID CONCENTRATIONS

\begin{tabular}{|c|c|c|c|c|c|c|c|c|}
\hline 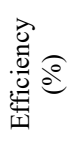 & $\begin{array}{l}\stackrel{\tilde{N}}{\omega} \\
\text { 墕 }\end{array}$ & 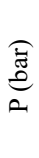 & 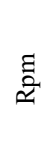 & 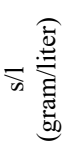 & 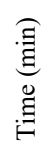 & 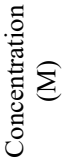 & 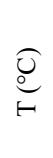 & 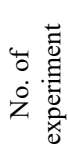 \\
\hline 15 & +1 & 10 & 600 & 40 & 120 & 0.25 & 120 & 1 \\
\hline 30 & +1 & 10 & 600 & 40 & 120 & 0.50 & 120 & 2 \\
\hline 52 & +1 & 10 & 600 & 40 & 120 & 1 & 120 & 3 \\
\hline 66 & +1 & 10 & 600 & 40 & 120 & 1.5 & 120 & 4 \\
\hline
\end{tabular}


TABLE VII. COMPARISON OF DISSOLVING RESULTS AT VARIOUS RPMS

\begin{tabular}{|c|c|c|c|c|c|c|c|c|}
\hline 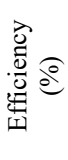 & 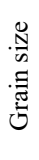 & 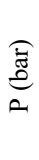 & ڤ્a & 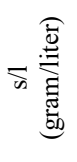 & $\begin{array}{l}\widehat{. \Xi} \\
\underset{\Xi}{\Xi} \\
\stackrel{\Xi}{\Xi}\end{array}$ & 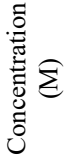 & $\underbrace{0}_{\mathfrak{r}}$ & 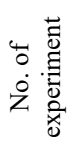 \\
\hline 80 & +1 & 10 & 600 & 40 & 120 & 1.5 & 120 & 1 \\
\hline 73 & +1 & 10 & 300 & 40 & 30 & 1.5 & 120 & 2 \\
\hline
\end{tabular}

\section{CONCLUSION}

The present study dealt with the recovery of nickel form direct reduction reformer catalyst using the pressurized dissolution in nitric method. The $\mathrm{NiO} / \mathrm{Al}_{2} \mathrm{O}_{3}$ spent catalyst considered in this study was used in the direct reduction relief gases catalysts for production of sponge iron. The parameters of temperature, concentration of acid, time and Rpm were investigated via pressurized dissolution method. Results showed that at $140{ }^{\circ} \mathrm{C}$ maximum dissolution can be obtained but over this optimum temperature a reverse effect is noticed. Another important factor is the Rpm change effect, as a change from 600 to 300 caused a decrease of $10 \%$ of dissolution efficiency. Finally, it is shown that efficiency was improved when dissolution time increased.

\section{REFERENCES}

[1] J. Y. Lee, S. V. Rao, B. N. Kumar, D. J. Kang, B. R. Reddy.,’Nickel recovery from spent Raneynickel catalyst through dilute sulfuric acid leaching and soda ash precipitation", Journal of Hazardous Materials, Vol. 176, pp. 1122-1125, 2009
[2] R. P. Silvy, "Future trends in refining catalyst market", Appl. Catal., Vol. 261, pp. 247-252, 2004

[3] P. Dufresne, "Hydroprocessing catalysts regeneration and recycling", Appl. Catal. A: Gen., Vol. 322, pp. 67-75, 2007

[4] M. Marafi, A. Stanislaus, "Spent catalyst waste management: A review: Part I-Developments in hydroprocessing catalyst waste reduction and use", Resources, Conservation and Recycling, Vol. 52, No. 6, pp. 859873,2008

[5] J. Idris, M. Musa, C. Y. Yin, K. H. Hamid, "Recovery of nickel from spent catalyst from palm oil hydrogenation process using acidic solutions", Journal of Industrial and Engineering Chemistry, Vol. 25, No. 16, pp. 251-5, 2010

[6] W. Mulak, A. Szymczycha, A. Lesniewicz, W. Zyrnicki, "Preliminary results of metals leaching from a spent hydrodesulphurization (HDS) catalyst", Physicochemical Problems of Mineral Processing, Vol. 40, pp. 69-76, 2006

[7] D. D. Sun, J. H. Tay, C. Easton, "Recovery and encapsulation of heavy metals on refinery spent hydrotreating catalyst", Water Science and Technology, Vol. 42, pp.71-7, 2000

[8] M. Marafi, A. Stanislaus., "Spent hydroprocessing catalyst management: A review, Part II-Advances in metal recovery and safe disposal methods", Resources, Conservation and Recycling, Vol. 53, pp. 1-26, 2008

[9] K. H. Park, D. Mohapatra, C. Nam.,'Two stage leaching of activated spent HDS catalyst and solvent extraction of aluminium using organophosphinic extractant, Cyanex 272", Journal of Hazardous Materials, Vol. 148, pp. 287-295, 2007

[10] D. Mishra, D. J. Kim, D. E. Ralph, J. G. Ann, Y. H. Rhee, "Bioleaching of spent catalysts using cidophilic bacteria and its kinetic aspect", Journal of Hazardous Materials, Vol.152, pp. 1082-91, 2008

[11] V. Bosio, M. Viera, E. Donati, "Integrated bacterial process for the treatment of a spent nickel catalyst", Journal of Hazardous Materials, Vol. 154, pp. 804-810, 2008 